\title{
Adolescent Pregnancy Prevention Behavior in Indonesia: Internal and External Factors Influencing
}

\author{
Deswinda Deswinda ${ }^{1}$, Rizanda Machmud ${ }^{2}$, Yusrawati Yusrawati ${ }^{3}$, Ahmad Syafruddin Indrapriyatna $^{4}$, Bayhakki Bayhakki ${ }^{5 *}$ \\ ${ }^{1}$ Department of Nursing, Institute of Health Sciences of Payung Negeri, Pekanbaru, Indonesia; ${ }^{2}$ Department of Public Health, \\ Faculty of Medicine, Andalas University, Padang, Indonesia; ${ }^{3}$ Department of Obstetric and Gynecology, Faculty of Medicine, \\ Andalas University, Padang, Indonesia; ${ }^{4}$ Department of Industrial Engineering, Faculty of Engineering, Andalas University, \\ Padang, Indonesia; ${ }^{5}$ Department of Medical-Surgical Nursing, Faculty of Nursing, Riau University, Indonesia
}

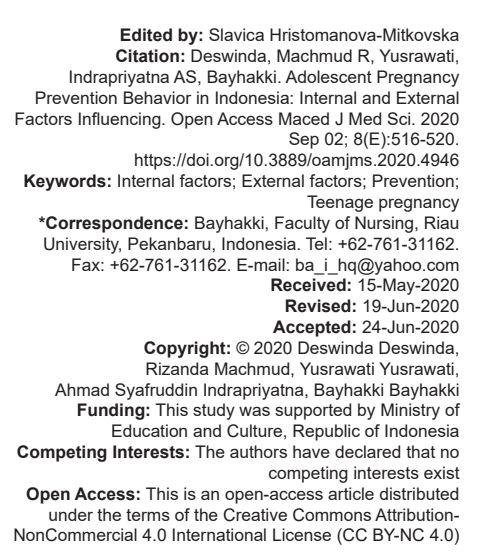

\begin{abstract}
BACKGROUND: The reasons behind teenage pregnancy and marriage in Indonesia are the lack of life skills and low self-efficacy. Teenagers with a lack of life skills are more likely to be influenced by their peers, in this case, to have sex before marriage. Teenage pregnancy often leads to a high rate of maternal and infant mortality and high-risk infants.

AIM: This study aimed to identify internal and external factors influencing adolescent pregnancy prevention behavior.

METHODS: This quantitative study with a cross-sectional design recruited 398 adolescents using a multistage sampling technique. Chi-square test and logistic regression test were employed with $p<0.05$.

RESULTS: The odds ratio (OR) value from the exponent $\beta$ with confidence interval $95 \%$. More than half of respondents $(64 \%)$ have behavior that might lead to teenage pregnancy, with both male and female respondents having equal risk $(p=0.920)$. Variables of knowledge, attitudes, self-efficacy, life skills, and peer influence were associated with adolescent pregnancy prevention behavior as all of them have a $p=0.000$. Moreover, peers were found to be the most influential variable of teenage pregnancy prevention behavior with the OR value of 3.84 , the highest among other variables which meant adolescents receiving negative influence from their peers are 3.84 times more likely to conceive at a young age. Peers become the most dominant factor in determining adolescent behavior in preventing pregnancy.

CONCLUSION: Among the variables related to prevention behavior, peers were found to be the one that will primarily
\end{abstract} determine adolescent behavior in terms of pregnancy prevention.

\section{Introduction}

Teenage pregnancy refers to a pregnancy that resulted from either a pre-marital or married process occurring between the ages of 14-19 years. Around 16 million girls aged 15-19 years and 2.5 million girls under 16 years gave birth and the number of babies born to adolescent mothers remains high in various countries [1], [2]. Data show, for example, that the childbirth rates were about 10.6 per 1000 girls in Massachusetts and 39.5 per 1000 girls in Arkansas in 2014 [3]. In Indonesia, the age-specific fertility rate for teens aged $15-19$ years is 36 per 1000 women [4]. Moreover, about 13.1\% women had their first pregnancy at ages 15-19, and $36.7 \%$ women at the age range had given birth once [5].

Sexual intercourse and an increase in active sexual behavior among adolescents contribute to teenage marriage and pregnancy. Figure shows that only $45 \%$ of young, unmarried women aged $15-19$ years knew the right place to go for adolescent information and counseling, signaling a lack of innovative services and guidance on reproductive health. Moreover, the life skills and life-efficacy of Indonesian teenagers are relatively poor, which renders them susceptible to risky behavior such as pre-marital sex among peer friends [4]. This is evident from a study concerning reasons for sexual intercourse. About $57.5 \%$ men said to have sex due to curiosity, while about $38 \%$ girls confessed that it just happened, and another $12.6 \%$ admitted being forced by their partner [5].

Teenage pregnancy leads to a high rate of maternal mortality, infant mortality, and various risks for babies. Therefore, strategies to prevent teen pregnancy, which include enhancing knowledge and building positive attitudes as well as personal development, are of prime importance [6]. These pregnancy prevention strategies were proven effective in reducing the risk of teenage pregnancy, as some individual states in the United States, for example, saw a successful reduction of $82 \%$ in the number of adolescent pregnancy [7]. The goal of the teen pregnancy prevention program in Indonesia is to improve understanding, abilities, and skills about adolescent reproductive health manifested through programs such as health promotion and adolescent counseling.

The programs should ideally be immediate to identify the most influential variable that brings about 
teenage pregnancy. A study on the subject is, therefore, necessary so as to address the problem of adolescent pregnancy immediately and effectively. Based on the background, this research seeks to establish the effect of internal and external factors on teenage pregnancy prevention behavior. It was developed based on the theory of adolescent prevention strategies, which suggests if adolescents desire to graduate from high school and intend to continue to college, they need to consider the possibility of unplanned pregnancy resulted from a harmful relationship that may hamper the achievement of these desires [8]. The objective of this study was to investigate the most influential variable of adolescent pregnancy prevention behavior. The specific purpose is to determine the effect of knowledge, attitudes, self-efficacy, life skills, and peer influence on the said behavior.

\section{Methods}

\section{Research location and participants}

The population of this first phase of the study was all adolescents in Rumbai sub-district, Pekanbaru, Indonesia. Calculation of sample size used a sample size formula which resulted in a sample size of 398 adolescents. The samples were collected on the basis of multistage cluster sampling technique, which is a random selection of groups of individuals in the population that naturally exist in a region [9]. The sampling technique consisted of 3 stages. Stage 1: A sub-district was selected randomly from 12 sub-districts in the city of Pekanbaru. Stage 2: The selected subdistrict consisted of 7 villages and one village was taken using a simple random sampling technique. Stage 3: From the selected village, the proportion of the respondents in each Hamlet of the village is determined based on the total number of samples.

\section{Instruments}

A questionnaire was used as the instrument to collect data. It was developed from the illustrative questionnaire for interview-surveys with young people designed by Clealand, Ingham, and Stone (2001) [10]. The age, sex, religion, and ethnicity of the teenagers were taken into the questionnaire. Specifically, the authors aim to collect data on knowledge, attitudes, selfefficacy, life skills, and peer influence regarding sexual relations. The respondents were advised of the matter of consent and how to fill out the questionnaire before completing it. Afterward, the researchers waited in place until the respondents finished the questionnaire. As the issue of reproductive health is sensitive, teachers were not involved during the process of data collection, aiming to maintain the objectivity of the answers. The questionnaire relies on the Likert scale with measurable indicators to ensure validity in designing questions or statements that require answers from respondents.

The validity and reliability of the data collection tool in this study were tested using Pearson Product Moment method. If the value of $r$ of results is greater than $r$ of table, the questions in the questionnaire are valid. In testing the reliability of the questions, the Cronbach's alpha method was used, whereby the value of alpha and value of table rare compared. If alpha is found to be greater than $r$ of table, the questions are declared reliable. The value of $r$ of table for 30 respondents with a $5 \%$ reliability level is 0.361 . To assess whether the questions are valid and reliable, the questionnaire was handed to 30 adolescents required to answer six parts, namely: (1) Questionnaire about knowledge of reproductive health and prevention of teenage pregnancy with a validity value of $0.453-0.833$ and a reliability value of 0.954 ; (2) questionnaire about attitudes toward pre-marital sexual behavior with a validity value of $0.469-0.792$ and reliability value 0.935 ; (3) questionnaire about self-efficacy to prevent pregnancy and abortion with a validity value of $0.500-0.870$ and reliability value 0.960 ; (4) life skills questionnaire on pregnancy prevention with a validity value of $0.564-0.819$ and reliability value 0.898; (5) questionnaire about the influence of peers on reproductive health with a validity value of $0.381-0.818$ and reliability value 0.940 , and (6) teenage pregnancy prevention questionnaire with a validity value of 0.489 0.809 and reliability value 0.743 .

The results of the validity test showed that all indicators on each variable studied have a value of $r$ greater than the $r$ of table, which means that all questions on the questionnaire are valid. Likewise, all indicators on each variable have a Cronbach's alpha value greater than 0.361 , suggesting the reliability of the questions.

\section{Procedure}

Data were collected by ten enumerators divided into five teams; all of them hold a Bachelor's degree in Nursing. Each team collected the data at different times, and researchers constantly monitored the process, received reports, and checked the completeness of each questionnaire from each team.

\section{Data analysis}

Univariate analysis was carried out on the basis of demographic characteristics, knowledge, attitudes, self-efficacy, life skills, and peer influence on the reproductive health issue. The results of analysis were displayed in the form of proportions and frequency distributions for each variable. In addition, bivariate analysis was done to examine the relationship between these variables with adolescent pregnancy prevention behavior, with the statistical test being used as the tool. Finally, the researchers conducted 
a multivariate analysis to establish the relationship between independent variables taken together with the dependent variable - which independent variables had the biggest contribution to the dependent variable. It was done by calculating the odds ratio (OR) with a logistic regression test.

\section{Ethics}

The study was approved by the Health Research Ethics Committee, Faculty of Medicine Andalas University, Padang, Indonesia (approval no. 480/KEP/FK/2018) and written informed consent was obtained from each participant before data collection conducted.

\section{Results}

Table 1 - Gender of the respondents was not significant to adolescent pregnancy prevention behavior with $p=0.920$. It means both male and female have equally risky behavior that may lead to teenage pregnancy.

Table 1: The relationship between characteristics with adolescent pregnancy prevention behavior $(n=398)$

\begin{tabular}{|c|c|c|c|c|c|c|c|}
\hline \multirow[t]{2}{*}{ Variable } & \multicolumn{2}{|c|}{ Not risky } & \multicolumn{2}{|c|}{ Risky } & \multirow[t]{2}{*}{ Total } & \multirow[t]{2}{*}{$\%$} & \multirow[t]{2}{*}{$\mathrm{p}$-value } \\
\hline & $\mathrm{n}$ & $\%$ & $n$ & $\%$ & & & \\
\hline Age (year) & & & & & & & 0.001 \\
\hline Early teens $(10-16)$ & 75 & 46.6 & 86 & 53.4 & 161 & 100 & \\
\hline Late teens $(17-25)$ & 69 & 29.1 & 168 & 70.9 & 237 & 100 & \\
\hline Gender & & & & & & & 0.920 \\
\hline Man & 58 & 36.5 & 101 & 63.5 & 159 & 100 & \\
\hline Women & 86 & 36.0 & 153 & 64.0 & 239 & 100 & \\
\hline Religion & & & & & & & 0.021 \\
\hline Islam & 110 & 40.7 & 160 & 59.3 & 270 & 100 & \\
\hline Catholic & 20 & 23.5 & 65 & 76.5 & 85 & 100 & \\
\hline Protestant & 9 & 26.5 & 25 & 73.5 & 34 & 100 & \\
\hline Hindu & 3 & 75.0 & 1 & 25.0 & 4 & 100 & \\
\hline Buddha & 2 & 50.0 & 2 & 50.0 & 4 & 100 & \\
\hline Confucius & 0 & 0 & 1 & 100 & 1 & 100 & \\
\hline \multicolumn{8}{|l|}{ Ethnic } \\
\hline Minang & 74 & 45.7 & 88 & 54.3 & 162 & 100 & 0.019 \\
\hline Malay & 37 & 27.2 & 99 & 72.8 & 136 & 100 & \\
\hline Java & 23 & 32.4 & 48 & 67.6 & 71 & 100 & \\
\hline Batak & 9 & 33.3 & 18 & 66.7 & 27 & 100 & \\
\hline Chinese & 1 & 50.0 & 1 & 50.0 & 2 & 100 & \\
\hline
\end{tabular}

Table 2 - The internal factors (knowledge, attitudes, self-efficacy, and life skills) and external factors (peer influence) were found to be associated with adolescent pregnancy prevention behavior with a value of $p=0.000$.

Table 2: The relationship between internal and external factors with adolescent pregnancy prevention behavior $(n=398)$

\begin{tabular}{|c|c|c|c|c|c|c|c|c|}
\hline \multirow[t]{2}{*}{ Variable } & \multicolumn{2}{|c|}{ Not risky } & \multicolumn{2}{|c|}{ Risky } & \multirow[t]{2}{*}{ Total } & \multirow[t]{2}{*}{$\%$} & \multirow[t]{2}{*}{$\mathrm{p}$-value } & \multirow[t]{2}{*}{ OR (Cl 95\%) } \\
\hline & $\mathrm{n}$ & $\%$ & $\mathrm{n}$ & $\%$ & & & & \\
\hline \multicolumn{9}{|l|}{ Knowledge } \\
\hline Good & 105 & 51.0 & 101 & 49.0 & 206 & 100 & \multirow[t]{2}{*}{0.000} & \multirow{2}{*}{$4.07(2.61-6.36)$} \\
\hline Poor & 39 & 20.3 & 153 & 79.7 & 192 & 100 & & \\
\hline \multicolumn{9}{|l|}{ Attitudes } \\
\hline Positive & 90 & 51.7 & 84 & 48.3 & 174 & 100 & \multirow[t]{2}{*}{0.000} & \multirow[t]{2}{*}{$3.37(2.20-5.16)$} \\
\hline Negative & 54 & 24.1 & 170 & 75.9 & 224 & 100 & & \\
\hline \multicolumn{9}{|l|}{ Self-efficacy } \\
\hline Able & 102 & 50.2 & 101 & 49.8 & 203 & 100 & \multirow[t]{2}{*}{0.000} & \multirow{2}{*}{$3.67(2.37-5.70)$} \\
\hline Less able & 42 & 21.5 & 153 & 78.5 & 195 & 100 & & \\
\hline \multicolumn{9}{|l|}{ Life skills } \\
\hline Skilled & 91 & 50.3 & 90 & 49.7 & 181 & 100 & \multirow[t]{2}{*}{0.000} & \multirow[t]{2}{*}{$3.12(2.04-4.78)$} \\
\hline Less skilled & 53 & 24.4 & 164 & 75.6 & 217 & 100 & & \\
\hline \multicolumn{9}{|l|}{ Peer influence } \\
\hline Positive & 90 & 56.6 & 69 & 43.4 & 159 & 100 & \multirow[t]{2}{*}{0.000} & \multirow[t]{2}{*}{$4.46(2.88-6.91$} \\
\hline Negative & 54 & 22.6 & 185 & 77.4 & 239 & 100 & & \\
\hline
\end{tabular}

Table 3 - Of the five variables, it is clear that the peers have the greatest influence on the risk of adolescent pregnancy, as shown by its OR value which is the highest (3.84) compared to OR values of other variables. This implies adolescents receiving negative influence from peers are 3.84 times more likely to have a teen pregnancy. Similarly, in the variable of attitudes, teens having negative attitudes of pre-marital sexual behavior are 2.19 times more likely to conceive at a young age compared to those who have positive attitudes.

Table 3: Results of analysis after final stage modeling

\begin{tabular}{lllll}
\hline No & Variable & p-value & OR & Cl (95\%) \\
\hline 1. & Knowledge & 0.035 & 1.79 & $1.04-3.10$ \\
2. & Attitudes & 0.006 & 2.19 & $1.25-3.84$ \\
3. & Self-efficacy & 0.046 & 1.73 & $1.00-2.99$ \\
4. & Life skills & 0.022 & 1.87 & $1.09-3.19$ \\
5. & Peer influence & 0.000 & 3.84 & $2.26-6.51$ \\
\hline
\end{tabular}

\section{Discussion}

Respondents' knowledge about reproductive health, in general, was almost partially stated to be low at $48.2 \%$, although $51.8 \%$ were stated to have high knowledge, only 14 points adrift. The findings on the variable of knowledge suggest that there was a relationship between knowledge of reproductive health with the risk of teenage pregnancy. This is consistent with Erikson's theory of psychosocial development that adolescents from 12 to 21 years old can face a psychosocial crisis known as identity confusion especially if they play a secondary role as a prospective mother due to adolescent pregnancy as they perceive the pregnancy as unintentional [11]. Pregnancy is often associated with individual characteristics such as knowledge, maturity, skills, and age when individuals have the first sexual intercourse [12]. Therefore, education plays an important role in developing self-confidence, increasing the age at which individuals have the first sex and thus delaying marriage. However, it also provides opportunities for pre-marital sexual activity that may lead to the risk of unwanted pregnancy, where knowledge of the body and contraception are insufficient [13].

When pregnancy occurs, girls and boys will generally be in the state of a dilemma over the pregnancy [14]. Permissive attitude to sex before marriage is closely related to teenage pregnancy as adolescents are exposed to activities that allow sexual intercourse to happen. The biological urge to do sex due to mutual attraction between two adolescents undeniably leads to sexual activities, thereby increasing the risk of pregnancy and sexual diseases. When they already have a firm belief and attitude to say nor for premarital sex, the risks will be extremely unlikely to occur.

The term self-efficacy in this study is as a concept of faith of an individual adolescent that 
determines whether or not they are able to prevent sexual intercourse. This belief is a parameter in determining the skills of a teenager, and this is related to teenage pregnancy prevention behavior. The actual problem occurring in the society is that teens are close to sex-related activities, for example, when they date with a friend of the opposite sex. In that instance, the risks of pre-marital sexual penetration, pregnancy, or contracting sexually transmitted diseases will automatically be present. It is the adolescents' belief of religious value that they can and should avoid sexual activity which should be fortified.

Basically, life skills are adaptive and positive behavior which allows individuals to cope with demands and challenges in life. They are an embodiment of the belief which is important in meeting the everyday demands of adolescent life. In this context, life skills are central to deter or control the urge for, for example, watching porn videos and rejecting activities that can lead to sexual arousal (hugging, kissing, and touching sensitive parts of body).

This study found that peers hold significant influence on the behavior of teenage pregnancy prevention, and this is consistent with the view that adolescence is a critical period during which individuals learn to develop and maintain intimate relationships with those of their age, explore desires, and negotiate sexual relations [15]. Nevertheless, this exploration period can also be a sexually risky period as they make critical decisions such as practicing unsafe sex and engaging in short-term intimacy that increases exposure to unwanted pregnancy and sexually transmitted diseases [16]. Understanding the susceptibility of each individual to peer influence is urgent to identify which adolescents are at risk of negative influences [17]. In fact, most teenage girls know at least one method of contraception, and the source of information is peer [13].

Compared to other examined variables, peer influence was the most influential in increasing or decreasing the risk of teenage pregnancy, with the highest OR value among all (3.84). This finding ultimately means that teens acquiring negative influence from peers have the possibility to conceive at a young age 3.84 times more than their counterparts who do not receive such influence. This is supported by the study which provides preliminary evidence on the central importance of peer influence in adolescent sexual behavior development. It also mentions that higher positive composite scores reflect greater vulnerability to peer influence regarding sex, while negative scores denote resistance to peer influence [18], [19], [20]. External variables in this study are limited to peers who influence the behavior of teenage pregnancy prevention while the role of parents, teachers, and health workers as facilitators and motivators are not included as determinant variables because of their indirect effect on adolescents.

\section{Conclusion}

Pregnancy prevention behavior in adolescents closely relates to internal variables that include knowledge, attitudes, life skills, self-efficacy, and an external factor which is peer influence. Among these variables, peers were found to be the one that will primarily determine adolescent behavior in terms of pregnancy prevention. Furthermore, sexual stimuli such as pornography and activities that encourage sexual arousal need to be strictly avoided so that adolescents will have self-efficacy and life skills to control their sexual urge. Thus, early sexual initiation that might lead to sexual intercourse and that increases the risk of teenage pregnancy can be prevented by adolescents themselves.

Based on a previous pilot study, teenagers with poor life skills have three times greater risk of pregnancy compared to the ones with good life skills and that teenagers with low self-efficacy have six times greater risk of pregnancy compared to the ones with high self efficacy [19]. Based on the research results also found, the Titeer game is proven to help respondents prevent teen pregnancy based on the measurement of the effect of the game on the value of teen pregnancy prevention [20].

\section{Acknowledgments}

The authors thank all participants who had participated in this study.

\section{References}

1. Loaiza E, Liang M. Adolescent Pregnancy: A Review of Evidence. New York: United Nations Population Fund; 2013.

2. World Health Organization. Adolescent Pregnancy. Geneva: World Health Organization; 2018.

3. FullerTR, WhiteCP, Chu J, DeanD, Clemmons N, ChaparroC, etal Social determinants and teen pregnancy prevention: Exploring the role of nontraditional partnerships. Health Promot Pract. 2018;19(1):23-30. https://doi.org/10.1177/1524839916680797 PMid:27913658

4. Center for Population Research and Development. Indonesia Demographic and Health Survey 2017: Adolescent Reproductive Health Key Indicators Report. Jakarta: National Population and Family Planning Board; 2018. https://doi.org/10.25133/ jpssv27n3.0016

5. Ministry of Health. Information Data of Indonesian. Jakarta: Ministry of Health; 2015.

6. Decker M, Berglas N, Brindis C. A call to action: Developing and strengthening new strategies to promote adolescent sexual health. Societies. 2015;5(4):686-712. https://doi.org/10.3390/ 


\section{soc5040686}

7. Koh H. The teen pregnancy prevention program: An evidencebased public health program model. J Adolesc Health. 2014;54(3 Suppl):S1-2. https://doi.org/10.1016/j.jadohealth.2013.12.031 PMid:24560068

8. Brindis CD, Sattley D, Mamo L. From Theory to Action Frameworks for Implementing Community-Wide Adolescent Pregnancy Prevention Strategies. San Francisco, CA: University of California, San Francisco, Bixby Center for Reproductive Health Research and Policy, Department of Obstetrics, Gynecology and Reproductive Sciences, and the Institute for Health Policy Studies; 2005. https://doi.org/10.21926/obm. neurobiol.2001053

9. Polit DF, Beck CT. Nursing Research: Generating and Assessing Evidence for Nursing Practice. $9^{\text {th }}$ ed. Philadelphia, PA: Lippincott, Williams \& Wilkins; 2012.

10. Cleland J, Ingham R, Stone N. Illustrative Questionnaire for Interview-Surveys with Young People. Asking Young People about Sexual and Reproductive Behaviors. Illustrative Core Instruments; 2001. Available from: http://www.who.int/ reproductivehealth/topics/adolescence/questionnaire.pdf. [Last accessed on 2018 Jun 30].

11. Shaffer DR, Kipp K. Developmental Psychology: Childhood and Adolescence. $9^{\text {th }}$ ed. Belmont, CA: Cengage Learning; 2014.

12. Ziyane IS, Ehlers VJ. Swazi youths' attitudes and perceptions concerning adolescent pregnancies and contraception. Health SA. 2006;11(1):31-42. https://doi.org/10.4102/hsag.v11i1.213

13. Brennan L, Mcdonald J, Shlomowitz R. Teenage births and final adult height of mothers in India, 1998-1999. J Biosoc Sci. 2005;37(2):185-91. https://doi.org/10.1017/ s0021932003006515
PMid:15768773

14. Lohan M, Cruise S, O'Halloran P, Alderdice F, Hyde A Adolescent men's attitudes in relation to pregnancy and pregnancy outcomes: A systematic review of the literature from 1980-2009. J Adolesc Health. 2010;47(4):327-45. https://doi. org/10.1016/j.jadohealth.2010.05.005

PMid:20864002

15. Kakkad A, Trivedi M, Trivedi G, Raichandani A. Study for adolescent problem and psychology. J Evol Med Dent Sci. 2014;3(37):9564-74. https://doi.org/10.14260/jemds/2014/3237

16. Kann L, Kinchen S, Shanklin SL, Flint KL, Hawkins, J, Harris WA, et al. Youth risk behavior surveillance-United States, 2013. Morb Mortal Wkly Rep. 2013;62(4):1-48.

17. Widman L, Choukas-Bradley S, Helms SW, Prinstein MJ. Adolescent susceptibility to peer influence in sexual situations. J Adolesc Health. 2016;58(3):323-9. https://doi.org/10.1016/j. jadohealth.2015.10.253

PMid:26794431

18. Choukas-Bradley S, Giletta M, Widman L, Cohen GL, Prinstein MJ. Experimentally measured susceptibility to peer influence and adolescent sexual behavior trajectories: A preliminary study. Dev Psychol. 2014;50(9):2221-7. https://doi. org/10.1037/a0037300 PMid:24999763

19. Deswinda D, Rizanda M, Yusrawati, Syafruddin IA. An analysis of the correlation between life skills and selfefficacy with the risk of teenage pregnancy. Indian J Public Health Res Dev. 2019;10(10):638-42. https://doi. org/10.5958/0976-5506.2019.02885.7

20. Deswinda, Machmud R, Yusrawati, Indrapriyatna AS. The Titeer game as an effort to prevent teen pregnancy. Enferm Clin. 2020;30:66-70. https://doi.org/10.1016/j.enfcli.2020.01.005 